\title{
Traditional and Modern Teaching Methodologies: Which One is More Successful and What are the Challenges?
}

\author{
Xhevahire Karanezi ${ }^{1}$ \\ Prof. Ass. Edmond Rapti² \\ Gentiana Halimi ${ }^{3}$ \\ 1PhD Candidate, University of Tirana, Faculty of Social Sciences, Department of Psychology and Pedagogy \\ 2University of Tirana, Faculty of Social Sciences, Department of Psychology and Pedagogy \\ 3University of Pristina \\ Email: xhevahirekaranezi@gmail.com
}

Doi:10.5901/ajis.2015.v4n2s2p311

\section{Abstract}

The changes in society raised the need to change the teaching methodologies in school. Therefore, the traditional teaching methodologies with teacher in the center were not anymore able to meet the needs of these changes. Focusing on promoting critical thinking, modern teaching methodologies, with the student in the center, are being implemented all over the world. The aim of this study was to investigate teachers' attitudes toward traditional and modern teaching methodologies such as RWCT, in terms of which one is more successful, more interesting for students and what are the main challenges for Kosovar teachers to practice RWCT techniques in their daily activities with students. This study used mixed methods of data collection (quantitative and qualitative methods). Questionnaire was used for collection of the quantitative data, while focus groups discussions with teachers were organized for qualitative data collection. 473 school teachers of primary and lower secondary schools in Kosovo were randomly selected to participate in this study. Additionally, four focus groups discussions were organized with school teachers to obtain in depth understanding of the issues. More than half of school teachers did not agree that "traditional teaching methodologies are more successful than modern teaching methodologies such as RWCT which one third of teachers agreeing with the above statement, with more than half of the teachers declaring that they prefer to use modern teaching techniques rather than traditional teaching techniques during their daily work with students. However, high numbers of students per teacher, overcrowded classrooms, environment, classroom organization, lack of trainings for teacher are some of the challenges that teachers face in using modern teaching methodologies in their daily work with students.

Keywords: Attitudes, Traditional Teaching, RWCT, Primary school, Lower secondary school

\section{Introduction}

According to Richards (2008), traditional teaching methodology was explained as learning that was mostly seen as under teacher's control. In this regard, the traditional classrooms were seen like ceremonial places where students sat in rows like spectators, while the teacher sat in front of them as a mayor or a priest (Crawford et al., 2005). Different from traditional teaching methodology, the modern teaching methodology such as RWCT is much more student-centered and it is focusing on promoting critical thinking. According to Scrivener (2005), the main role of the teacher in modern teaching methodology is to help students by encouraging, involving and helping them in the process of learning. The studentcentered teaching methodology is focused more on student's interests and their learning (Tzuo, 2007).

Nevertheless, the biggest problem facing teachers today is the lack of ability of most students to think critically. This could be due to the fact that critical thinking was not effectively promoted within traditional teaching environment which is mostly based on memorization (Nickerson, 1987; Kennedy, 1991; Paul, 1993).

Focusing on teaching methods for teacher, Critical Thinking about Reading and Writing (RWCT) is an initiative of the Open Society Institute (OSI) and the International Reading Association (IRA) that provides specific strategies for interactive teaching methods to help teachers to prepare their students in becoming active citizens in an open society (American Institute for Research, 2001). According to Kosovo Education Center (2011), RWCT is a modern teaching philosophy in which students are active participants in building up their knowledge through their involvement in research activities. It was found that students prefer more the classes of those teachers that give them more opportunity to actively 
participate in class activities and discussions (Rado, 2013). On the other hand, studies show that teachers have reported they benefit a lot in terms of their personal career by attending the RWCT program (Covac \& Cretu, 2010). Participation in this program has resulted with positive perceptions of teachers in regard to their teaching practice (Pupovci \& Taylor, 2003; Musai \& Wile, 2004; Rado, 2013). Moreover, the RWCT program not only had a major impact on teaching practices and student performance, but also in teachers' and learners attitudes about teaching (American Institute for Research, 2001). Regarding Kosovo, in the last decade, RWCT was one of the largest educational development programs, with high popularity, that reached out almost one fourth of all teachers in the country (Rado, 2013). However, studies have shown that primary school teachers reported different experiences in regard to RWCT implementation in their daily work with students, compared to lower secondary school teachers. It was found that lower secondary school teachers face more challenges on using the RWCT techniques in their daily work with students (Pupovci \& Taylor, 2003).

\section{Research Methodology}

The current study was conducted utilizing both quantitative and qualitative data collection methods. Questionnaires were used for collection of quantitative data whereas focus group discussions with school teachers were organized in order to obtain in depth information. In total 473 primary and lower secondary school teaches have participated in this study and additionally 4 focus group discussions were organized with primary and secondary school teachers.

\section{Participants}

This study was conducted in 23 primary and lower secondary schools in Kosovo from 6 different regions from urban and rural areas. From the total of 473 school teachers who participated in this study, 219 of them were of primary schools (grade 1-5) and 254 secondary school teachers (grade 6-9). A questionnaire was administrated to all school teachers who participated in this study. Additionally, 4 focus group discussion were conducted with primary and lower secondary school teachers, comprised of groups of 6 to 8 teachers of primary and lower secondary schools.

\section{Instruments}

For the purpose of quantitative data collection, a specific questionnaire was developed in accordance with the study objectives. Also, some of the questions were based on an existing questionnaire used by Pupovci and Taylor (2003). Prior to the data collection, a pilot study was conducted in order to test the developed questions. The pilot was conducted with primary and secondary school teachers from two schools not included in the study sample. The pilot resulted with few changes on questions formulation, and no recommendation on removing or adding new questions. Furthermore, semi structure questions for focus group discussions were developed, in which the discussion was structured.

\section{Procedure of data collection}

The data collection was conducted within school premises where questionnaire forms were administrated to teachers. Questionnaires were administrated to small groups of teachers in order to ensure teachers had enough space and privacy to fill in the questionnaire. The research team was available during the whole time if any questions or issue was raised while teachers were filling in the questionnaires.

Moreover, focus group discussions were also conducted within school premises after official working hours. Prior to the discussion, all participants were asked to sign a consent form for participation in the focus group. Permission from participants was taken for recording the discussion.

\section{Results}

The data presented in Figure 1 presents teachers' responses to the statement, "Traditional teaching methodology is more successful compared to modern teaching methodology such as RWCT". The data presented below shows that only $9 \%$ of primary and school teachers in Kosovo totally agree with the statement indicating that traditional teaching methodology is more successful than modern teaching methodology and almost one third of teachers (35\%) somewhat agreeing with the above mentioned statement. On the other hand, more than $30 \%$ of primary and lower secondary school teachers totally disagree with the above statement indicating that traditional teaching methodology is not more successful than modern 
teaching methodology and $24 \%$ somewhat disagreeing with the statement.

Figure 1. Primary and lower secondary school teachers' responses to the statement: "Traditional teaching methodology is more successful compared to modern teaching methodology".

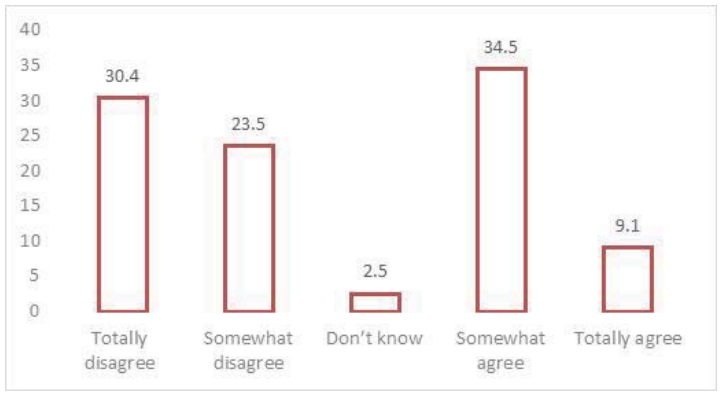

Table 1 presents teachers responses to the statement, "Traditional teaching techniques are more interesting for students than teaching according to modern teaching methodologies such as RWCT". As per the data presented below, almost one third (31\%) of teachers totally disagree with the given statement, indicating that traditional teaching techniques are not more interesting for students than modern teaching methodologies, while one fourth of teachers totally agreeing, indicating the opposite.

Table 1. Primary and lower secondary school teachers' responses to the statement, "Traditional teaching techniques are more interesting for students than teaching according to modern teaching methodologies such as RWCT".

$\begin{array}{lcc} & \text { Frequency } & \text { Percentage } \\ \text { Totally disagree } & 146 & 30.9 \% \\ \text { Somewhat disagree } & 90 & 19.0 \% \\ \text { Don't know } & 19 & 4.0 \% \\ \text { Somewhat agree } & 91 & 19.2 \% \\ \text { Totally agree } & 127 & 26.8 \% \\ \text { Total } & 473 & 100.0\end{array}$

In terms of which teaching methodology is more preferred by teachers, the data presented in Table 2 show that almost half of teachers declared that they preferred more modern teaching methodology rather than traditional teaching methodology, with only $11 \%$ of teachers declaring the opposite.

Table 2. Teacher's responses to the statement: "I prefer more working with traditional teaching methodology than modern teaching methodology such as RWCT"

$\begin{array}{lcc} & \text { Frequency } & \text { Percentage } \\ \text { Totally disagree } & 206 & 43.6 \% \\ \text { Somewhat disagree } & 93 & 19.7 \% \\ \text { Don't know } & 14 & 3 \% \\ \text { Somewhat agree } & 108 & 22.8 \% \\ \text { Totally agree } & 52 & 11 \% \\ \text { Total } & 473 & 100.0\end{array}$

\section{Findings from focus group discussions}

Findings from focus group discussions are in line with the quantitative results in terms of teachers' readiness to apply modern teaching methodologies in their daily work with students. However, based on the qualitative data this does not seem to be enough for teachers to regularly apply modern teaching techniques such as RWCT in their daily work. Some 
of the teachers declared that they did not participate in any RWCT training, and as such they have only managed to learn about these techniques either through friends/colleagues or learn itself. Hence, these teachers declared they need better understanding of how these new techniques work and should be applied with students.

Participant (1) "I personally would be very much interested to know more about RWCT techniques. All I have heard and learn about these techniques is mostly from my colleagues who have already attended RWCT trainings, or I have had the opportunity to watch my colleagues applying such techniques with their students."

Moreover, for the teachers who have undergone the RWCT training and do have the basic information its teaching techniques, there are other challenges that makes them difficult to apply. Overcrowded classrooms are one of the challenges teacher face on their everyday work, which makes very difficult application of modern teaching methodologies. Due to high number of students per classroom it is impossible for some of the techniques to be applied, as teachers do not have time to individually work with all the students and it is difficult to manage the students during work activities.

Participant (2) "Sometime, I really want to apply a certain technique but it is just impossible to manage 45 students in a small classroom..."

Lower secondary school teachers have declared facing environment/space challenges in particular. Considering that lower secondary school teachers are supposed to move from one classroom to another they stated that it is impossible to arrange/organize the classroom every time within the given time per class hour.

Participant (3) "Maybe these techniques are easier to be applied by primary school teachers who are responsible only for one classroom, have the same classroom everyday etc, but for us, working as lower secondary school teachers, who are supposed to move from one classroom to another every class hour is very difficult, as the time does not permitted just to organize the room. The desks are in lines every day we go to the classroom...so it just takes a lot of time and efforts to organize everything from the beginning"

Interestingly there were teachers stating that modern teaching techniques are not very useful as they bring noise in the classroom and are not suitable for students of lower secondary schools.

\section{Discussion}

This study aimed at investigating teachers attitudes toward traditional and modern teaching methodologies such as RWCT in terms of which is more successful, more interesting for students and identifying some of the challenges teachers face on practicing modern teaching methodologies in their daily work. The data showed that in general more than half of teachers did not agree with the statement that: "traditional teaching methodology is more successful than modern teaching methodology", from which $30 \%$ of totally disagreed compared to only $9 \%$ of those who totally agreed with the statement. The data showed that unfortunately teachers' awareness on the advantages of modern teaching methodologies is not yet universal. Moreover, in terms of teachers' attitudes toward which method is more interesting for their students, the data showed that almost a third of teachers fully disagree that traditional teaching methodologies are more interesting for their students compare to one fourth of teachers who declared the opposite. Teacher were also asked whether they prefer to use traditional or modern teaching methodologies (RWCT) in their daily work with students, from which almost half of teachers declared they prefer to use more modern teaching methodologies with only $11 \%$ of teachers declaring that they prefer using traditional teaching methodologies. Nevertheless, more in depth information were obtain by qualitative data, indicating teachers' challenges and misconceptions on application of modern teaching methodologies. Based on the findings from focus groups discussions it revealed that lack of teachers' training, overcrowded classrooms, space environment are the main challenges hindering the application of modern teaching methodologies such as RWCT in teachers' daily work with students. Findings from the focus groups discussions indicate some misconceptions regarding modern teaching techniques among primary and lower secondary teachers, such as modern techniques bring noise in the classrooms, are not suitable for younger children - students of lower secondary school.

\section{Conclusion}

Almost one third of primary and lower secondary school teachers totally disagreed with the statement that, "traditional teaching methodology is more successful than modern teaching methodology such as RWCT" with only $9 \%$ of teachers who totally agreed with the given statement. Almost one third of primary and lower secondary school teachers totally disagreed with the statement that, "traditional teaching methodology is more interesting than modern teaching methodology" while one fourth declared the opposite. In terms of teachers' preference of traditional versus modern 
teaching methodology, the data showed that almost half of teachers declared that they prefer modern teaching methodology while only $9 \%$ declared they prefer traditional teaching methodology. Lack of teachers' trainings, overcrowded classrooms, space environment, revealed as main challenges faced by teachers hindering the application of modern teaching methodology. Some of the main misconceptions in regard to modern teaching methodology indicated by the findings of the current study are some of the opinions of the teachers that modern techniques bring a lot of noise which make them not suitable for younger children, those of lower secondary school.

\section{References}

American Institute for Research. (2001a). The 2000-2001 Reading and Writing for Critical Thinking Project Impact and Institutionalization Study. New York: OSI.

Richards, J. C. (2008). Communicative Language Teaching Today. New York: Cambridge University Press.

Crawford, A., Saul, W., Mathews, S., \& Makinster, J. (2005). Teaching and Learning Strategies for the Thinking Classrooms. The International Debate Education Association.

Tzuo, P. W. (2007). The tension between teacher control and children's freedom in a child-centered classroom: Resolving the practical dilemma through a closer look at the related theories. Early Childhood Education Journal, 35(1), 33-39. doi: 10.1007/s10643-0070166-7.

Scrivener, J. (2005). Learning Teaching. Oxford: MacMillan.

Rado, P. (2013). The Evaluation of the Reading and Writing for Critical Thinking Program in Kosovo. Final Evaluation Report. Prishtinë: Kosova Education Center.

Pupovci, D., \& Taylor, A. (2003). Reading and Writing for Critical Thinking. Final Evaluation Report. Prishtinë: Kosova Education Centre. Qendra Për Arsim e Kosovës (KEC). (2011). Raporti i punës për vitin 2010. Prishtinë.

Musai B. \& Wile. J. (2004). Lesson from Albania: Professional Development that Transforms Educators, Schools and Communities. Mediterranean Journal of Educational Studies, Volume 9 Number 1, Malta.

Covac, M., \& Cretu, N. (2010). Critical Thinking Program Review. OSI.

Kennedy, M. (1991). "Policy Issues in Teaching Education." Phi Delta Kappan, 72.9: 661-666. Print.

Nickerson, R.S. (1987). "Why Teach Thinking?" Teaching Thinking Skills: Theory and Practice. Eds. J.B. Baron, \& R.J. Sternberg. New York: W.H. Freeman \& Company,. 27-37.

Paul, R.W. (1993). Critical Thinking: What Every Person Needs to Survive in a Rapidly Changing World. Santa Rosa, CA: Foundation for Critical Thinking. Print. 